\title{
Transformational Leadership and Job Satisfaction: The Mediating Role of Procedural Justice
}

\author{
Salem Mohamed A. Mansur \\ School of Economics and Management \\ Beihang University, Beijing, China \\ Higher Institute of Technology, Gasser Ben Ghachir, Libya \\ Salemalmashi2015@yahoo.com
}

\author{
Jia Guozhu \\ School of Economics and Management \\ Beihang University, Beijing, China \\ jiaguozhu@buaa.edu.cn
}

\begin{abstract}
The aims of this study were to identify the level of job satisfaction (JS) and the degree of transformational leadership (TLS) practice in technical colleges in western Libya, as well as detect the impact of TLS on job satisfaction. Additionally, verifying the role of procedural justice (PJ) as a mediating variable between TLS and job satisfaction. Consequently, to achieving the research objectives, the measurement tools were developed depending on previous studies. Moreover, a simple random sample of $\mathbf{1 5 9}$ faculty members was selected. The study found that the level of job satisfaction was medium and conversely of that the level of TLS practice was low. The results showed that TLS has a substantial and positive impact on job satisfaction. It also revealed that procedural justice partially mediates the relationship between TLS and job satisfaction. Finally, the study recommended improving job satisfaction by focusing on encouraging managers to adopt transformational leadership and adopting procedural justice principles.
\end{abstract}

Keywords-Transformational Leadership; Procedural justice; Job satisfaction; technical colleges; Libya

\section{INTRODUCTION}

The success of the organizations depends primarily on the leadership style and behaviors adopted by leaders. Consequently, scholars emphasize the key role of the organization's leadership in managing human resources and their ability to build an organizational environment that motivates and encourage them to work with sincere desire. Effective leadership is the leadership that can create a clear vision for the organization convinces subordinates. Scholars have argued that the transformational leadership owns a set of characteristics that qualify it to be an effective leader; transformational leadership provides motivation and inspiration, develops skills, takes into account the humanitarian and moral aspects, and gives good reward to subordinates. Accordingly, studies have shown that leadership patterns and the sense of organizational justice are key factors influencing job satisfaction [1]. In line with that, transformational leadership (TLS) as one of these patterns has been able to achieve great success in regard to subordinates discipline and accepting them to work and achieve goals through its different mechanisms. It sets a vision for the future, works to take opportunities, motivate the creative energies of the workers and increase their sense of commitment. As they can also change the organization's culture of desired trends, create trust between it and subordinates promote a sense of justice of all kinds and increase the values of loyalty to the organization. On the other hand, the issue of organizational justice has attracted the attention of researchers. Accordingly, most studies indicate that organizational justice with its dimensions is one of the most important factors affecting the organizations' success and other phenomena such, as job satisfaction and performance improvement [2]. In the past, financial resources played a critical role in the success of organizations, but at present ethics, quality of work life, job satisfaction, organizational justice, and other concepts have become determinants of the success and stability of organizations. [3]. In light of the above, the current study aims mainly to study the impact of TLS on job satisfaction and to determine whether the procedural justice variable mediates this relationship.

\section{THEORETICAL BACKGROUND}

\section{A. Transformational leadership}

TLS is defined as the leadership style that achieves organizational commitment to employees by giving them greater freedom to act and make decisions about their work [4]. Consequently, this concept was developed to describe leaders who transform and develop the work issues for the better by their ability to innovate and provide innovative ideas that lead to major changes in work performance. Accordingly, TLS a concept encompasses four dimensions which are (1) idealized influence; this dimension embodies the emotional element of TLS and indicates that TLS influences his subordinates by being a role models (2) inspirational motivation, this dimension relates to the ability of the transformational leader to activate his subordinates by meeting their basic requirements of selfesteem and achieving their goals [5], (3) intellectual stimulation, transformational leader helps his/her followers identify problems, challenge, deal with their abilities and encourage them for creativity, (4) individualized considerations, TLS treat each employee individually and takes into account the personal needs, abilities and desires of each employee advising and providing support when necessary.

\section{B. Transformational leadership and Job satisfaction.}

The interest in job satisfaction is due to the attempts of the organizations' management to ensure employees' loyalty and their support for the goals seeks to achieve. Therefore job satisfaction defined as a degree to which a person positively evaluates his/ her functional experiences [6]. Thus, the main 
indicator of job satisfaction is how leaders and subordinates feel about their jobs? [7]. It is a positive emotional state that appears as a resulting of a person's work or experience in the organization [8] While negative attitudes towards workers are formed if workers are dissatisfied with their jobs. Previous studies indicate that leadership style is one of the main factors that affect employee satisfaction. Some studies indicated that leader who holds idealized influence able to influence his followers which they deal with him and consider him as an example to them this, in turn, enhances their satisfaction [9]. The transformational leader acts through the idealized influence, motivate subordinates and influence their motivations which in turn affect the level of job satisfaction. On the other hand, by individual consideration, he provides support, encouragement, and training, which plays a key role in developing the abilities and skills of subordinates, which positively affects job satisfaction [10]. In addition, the inspiring motive enables the leader to instill pride in his followers and urge them to transcend their personal interests in favor of the organization, by intellectual stimulation, he encourages his subordinates to challenge, take risks, share knowledge, solve problems, and tolerate errors resulting from attempts to find innovative solutions to problems.

\section{Procedural justice and job satisfaction}

Organizational justice is one of the important and effective administrative concepts that have attracted the attention of many researchers for its great impact on the organization and its functions. Consequently, most of the literature dealing with the issue of organizational justice suggests that it includes three main dimensions: Procedural Justice, Interactional Justice, and Distributive Justice [11]. The present study focuses on the test of the dimension of procedural justice as a mediating variable in the relationship between transformational leadership and job satisfaction. Procedural justice refers to the behavior and processes used by the organization to perform the various functions and focuses on the procedures and laws through which the organizational outputs are distributed. Researchers identified a set of criteria that are relied upon to realize procedural justice includes : (1) Consistency, means stability and fairness in dealing with individuals (2) Unbiased, this means to apply the same procedures to all individuals targeted by a particular decision (3) Accurate, by scrutinizing in information before making procedural decisions (4) Correct, by correcting decisions in the case of appeals and complaints by individuals; (5) Representative, where such decisions must represent all individuals without exception; (6) Ethical, by respecting public principles and morals when applying procedures $[12,13]$. Many see that organizational justice by procedural justice dimension is one of the greatest determinants of job satisfaction through procedural and relationships in an organization [14]. The results of the studies indicate that the realization of organizational justice has a pivotal role in influencing many work outputs such as job satisfaction and organizational [15]. On the basis of the aforementioned theories and empirical studies, we hypothesized the following:

H1: Transformational leadership significantly influences on procedural justice among faculty members in technical education colleges in the western region of Libya.
H2: Procedural justice significantly influences on job satisfaction among faculty members in technical education colleges in the western region of Libya.

H3: Procedural justice mediates the relationship between transformational leadership and job satisfaction among faculty members in technical education colleges in the western region of Libya.

\section{METHOD}

The data were collected from a sample of 159 faculty members from 5 technical education colleges in the western region of Libya. Consequently, the questionnaire was designed based on previous studies relevant to the subject of the study by using the scales established by the researchers which showed high validity and reliability. Accordingly, the study tool consisting of 20 items measure TLS (MLQ - 5X Short Form) [16], the procedural justice was measured with 5 items by [17], as well as Job satisfaction was measured by 8 items adapted from [18]. All items were based on a 5-point Likert type scale, ranging from 1 (strongly disagree) to 5 (strongly agree). Moreover, all the data were analyzed using SPSS, version 23. On the other hand, the linear regression, and mediation analysis method suggested by Baron and Kenny [19] was employed to test hypotheses.

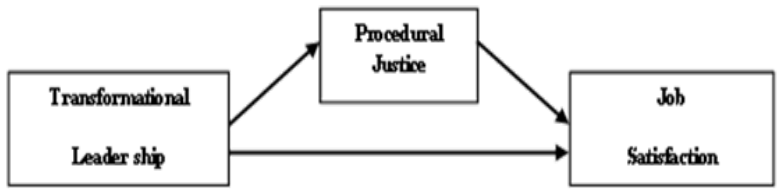

Fig. 1. Conceptual model of the study

\section{RESULTS}

First of all, a series of tests were carried out to verify the assumptions necessary for the regression analysis. The results showed that the data were appropriate and no violations were found for the application of the regression equations. In addition, reliability tests, descriptive statistics and correlation test were conducted between the study variables. The results are presented in Table I.

TABLE I. SD, CRONBACH ALPHAS AND CORRELATION MATRIX

\begin{tabular}{|c|c|c|c|c|c|}
\hline Variables & Mean & S .D & $\mathbf{1}$ & $\mathbf{2}$ & $\mathbf{3}$ \\
\hline Transformational Leader ship & 2.74 & $.42^{* *}$ & $(.92)$ & & \\
\hline Procedural Justice & 3.03 & $.41^{* *}$ & $.404^{* *}$ & $(.86)$ & \\
\hline Job Satisfaction & 3.06 & $.96^{* *}$ & $.503^{* *}$ & $.687^{* *}$ & $(.79)$ \\
\hline
\end{tabular}

The table shows that all the values of Cronbach's alphas for all study variables were high and acceptable and exceeded the assumed value of 0.70 as suggested by [20]. The results also show that all variables of the study are significantly correlated to each other. The mean value of transformational leadership 2.74 its lower than the mid-point of the scale, indicating that the faculty members believe that their leaders are displaying low levels of transformational leadership behaviors, as well as the mean values of procedural justice and job satisfaction respectively $(3.03,3.06)$, which means that 
there is a medium level of procedural justice and job satisfaction among faculty members in technical education colleges in western Libya.

Table II shows a simple regression analysis test of the first and second hypotheses. In the first model, we tested the relationship between TLS and procedural justice the results showed that TLs contributed positively and significantly to procedural justice $(\beta=.404, \mathrm{p}<.01), \mathrm{R}^{2}=.16 .3$. So, TLs explains $16.3 \%$ of the variance in procedural justice. In the second model we tested the relationship between procedural justice and job satisfaction, the results showed that the procedural justice influenced and contributed significant positive on job satisfaction, $(\beta=.687, \mathrm{p}<.01), \mathrm{R}^{2}=.47 .3$. So, procedural justice explains $.47 .3 \%$ of the variance in job satisfaction. Therefore, the first and second hypotheses are accepted.

TABLE II. SIMPLE REGRESSION TEST, H1, H2

\begin{tabular}{|c|c|c|c|c|c|c|}
\hline Dep. V & Ind.v & B & T & $\mathbf{R}^{\mathbf{2}}$ & $\mathbf{R}^{\mathbf{2}}$ adj & F \\
\hline (PJ) Equation 1 & TLS & .404 & 5.529 & .163 & .158 & 30.567 \\
\hline (JS) Equation 2 & PJ & .136 & 11.861 & .473 & .469 & 140.68 \\
\hline
\end{tabular}

(Dep. V) Dependent Variable, (Ind. V) Independent Variable. $\mathrm{p}<.01$.

In order to test the mediator role of the procedural justice variable between the transformational leadership and the job satisfaction variable, the researcher adopted the steps and the conditions identified by Baron and Kenny according to the following: (a) there should be a significant effect between independent variable and mediator variable; (b) there should be a significant effect between independent variable and dependent variable; (c) there should be a significant effect between mediator variable and dependent variable with the independent variable as a control variable, this condition includes two aspects: If the beta value reduced when the mediator variable enters, this means there is a partial mediation role. If the beta value (zero-effect) in the equation, it means there is a full mediation role between the independent variable and dependent variable.

Based on the above, and in the light of the results of Table II, it turns out the achievement of the first and second conditions of with regard to the relationship between the independent variable (transformational leadership) and the intermediate variable (procedural justice).

In the second step were entered variables successively as shown in Table III.

TABLE III. TLS AS PREDICTOR PROCEDURAL JUSTICE AS A MEDIATOR.

\begin{tabular}{|c|c|c|c|c|c|c|c|}
\hline \multicolumn{2}{|c|}{ Model } & \multirow{2}{*}{$\frac{\mathbf{B}}{.503^{* *}}$} & \multirow{2}{*}{$\frac{\mathbf{T}}{7.293^{* *}}$} & \multirow{2}{*}{$\begin{array}{l}\mathbf{R} \\
.50\end{array}$} & \multirow{2}{*}{$\begin{array}{l}\mathbf{R}^{2} \\
.25\end{array}$} & \multirow{2}{*}{$\begin{array}{c}\mathbf{R}^{2} \mathbf{a d j} \\
.248\end{array}$} & \multirow{2}{*}{$\frac{\mathbf{F}}{53.190^{* *}}$} \\
\hline 1 & TLS & & & & & & \\
\hline \multicolumn{8}{|c|}{ Equation 2 : procedural justice as a mediating } \\
\hline \multirow{2}{*}{2} & TLS & $.269 * *$ & $4.507 *$ & \multirow{2}{*}{\multicolumn{4}{|c|}{$\begin{array}{r}\mathrm{R}=.730 \quad \mathrm{R}^{2}= \\
\mathrm{R}^{2} \text { adj }=.527 \\
\mathrm{~F}=89.153^{* *}\end{array}$}} \\
\hline & $\mathrm{PJ}$ & $.579 * *$ & $9.680 * *$ & & & & \\
\hline
\end{tabular}

In the first model, the relationship of TLS with job satisfaction was tested; the results showed that TLS has a significant and positive effect on job satisfaction, where $(\beta$
$=.503, \mathrm{p}<.01) \mathrm{R}^{2}=.253$ indicates that the independent variable interprets $25.3 \%$ of the variance in the dependent variable and the possibility of circulating the model to another research community.

On the other hand, the relationship between TLS and job satisfaction is a linear relationship this means the validity of the model to predict variance in the dependent variable. Based on this finding, the third condition of mediation was achieved. In the second model, the procedural justice variable was added to the regression equation. The table shows that the value of beta in the second equation was less than its value in the first equation with its survival statistically significant, which means that the procedural justice variable partially mediates the relationship between transformational leadership and job satisfaction

\section{DISCUSSION}

The aim of this study was to identify the impact of TLS on job satisfaction and examine the role of procedural justice as a mediating. The findings of the study proved that transformational leadership has an important role in supporting job satisfaction. Consequently, our finding is in line with some previous studies considered that TLS supporting subordinates' job satisfaction [21, 22].

On the other hand, the findings showed that procedural justice partially mediates the relationship between TLS and job satisfaction $\left(\mathrm{R}^{2}=.53\right)$, it means both TLS and procedural justice, explain 53.\% of variance in job satisfaction, while the direct impact of TLS without the mediation of procedural justice, explains only $25 \%$ of variance in job satisfaction $\left(\mathrm{R}^{2}\right.$ $=.53$ ). Accordingly, procedural justice works as a variable strengthens this relationship. Our results consistent with the previous results of $[3,23]$. Thus the results of the study confirm that justice has a key role in motivating individuals to integrate into their organizations because the realization of justice sends a message that they feel there is a state of respect and appreciation from the organization and their administration. The research hypotheses proved this fact, which reported the positive role of procedural justice, which is one of the components of organizational justice in increasing the level of job satisfaction.

\section{CONCLUSION}

The findings of the current study showed transformational leadership directly positively affects job satisfaction and indirectly through the role of procedural justice as a mediator, where the study confirmed the partial mediation role of procedural justice in the relationship between the transformational leadership and job satisfaction. This means that transformational leadership is able to enhance its role on job satisfaction via procedural justice, which means that it is possible to develop the theory of transformational leadership and improve its performance through the use of other elements act as mediation variables for enhancing its performance. Based on the findings of the study, the study recommends that managers should be encouraged to practice the pattern of transformational leadership with its characteristics and behaviors practices as it is one of the most impact leadership styles on organization effectiveness and increase sense of the 
procedural justice, as well as it is one of the most leadership methods to take into account the human and productive aspects together. On the other hand, managers should also be trained to practice transformational leadership, where Bass believes that transformational leadership skills can be acquired by education and training, also job satisfaction should be promoted for faculty members and remove the causes of tension and dissatisfaction as well the sense of procedural justice should be promoted by procedures and decisions based on accurate information and achievement of fairness in personal relations and non- aligned. As the case of each study, our study has a limitation; the application of this study was limited to sample members of the teaching staff in the west and did not include samples from other regions for the difficulty of communication, due to instability of the country. Therefore, it limits the ability to generalize the results, on other hands, the data were collected at a cross-sectional and therefore the researcher suggests collecting data from the respondents at more cross-sectional, where the use of this method is expected to help a greater understanding of the nature of the relationship between variables of the study.

\section{REFERENCE}

[1] Zhu W, Sosik JJ, Riggio RE, Yang B. Relationships between transformational and active transactional leadership and followers organizational identification: The role of psychological empowerment. Journal of Behavioral and Applied Management. 2012 May 1;13(3):186.

[2] Alatwi, A, Hussein. The Impact of Organizational Justice in Contextual Performance: An Analytical Study for Teaching Staff Members Faculty of Management and Economics - University of Qadisiyah, magazine Qadisiyah Of Administrative and Economic.2007 Vol. 10, Issue 1.

[3] Koonmee K, Singhapakdi A, Virakul B, Lee DJ. Ethics institutionalization, quality of work life, and employee job-related outcomes: A survey of human resource managers in Thailand. Journal of business research. 2010 Jan 1;63(1):20-26.

[4] Riaz A, Haider MH. Role of transformational and transactional leadership on job satisfaction and career satisfaction. Business and Economic horizons. 2010 Apr 1;1(1):29-38.

[5] Mittal S, Dhar RL. Transformational leadership and employee creativity: mediating role of creative self-efficacy and moderating role of knowledge sharing. Management Decision. 2015 Jun 15;53(5):894-910.

[6] Yang YF. Examining competing models of transformational leadership, leadership trust, change commitment, and job satisfaction. Psychological Reports. 2016 Aug;119(1):154-73.

[7] Bawafaa E, Wong CA, Laschinger $H$. The influence of resonant leadership on the structural empowerment and job satisfaction of registered nurses. Journal of Research in Nursing. 2015 Nov;20(7):610622.
[8] Youssef CM, Luthans F. Positive organizational behavior in the workplace: The impact of hope, optimism, and resilience. Journal of management. 2007 Oct;33(5):774-800.

[9] Gitoho SW, Kamau JN, Muchara M. Influence of Transformational Leadership Style on Employee Job Satisfaction: Case Study of Firms Listed at the NSE 2016

[10] Belias D, Koustelios A. Transformational leadership and job satisfaction in the banking sector: A review. International Review of Management and Marketing. 2014 May 18;4(3):187-200.

[11] Rego A, Cunha M. Organizational Justice and Citizenship Behaviors: a Study in a Feminine, High Power Distance Culture, Submission of Papers for Publication, University de Santiago, Aveiro. Pro Quest, Retrieved on. 2006;28(5):2017.

[12] Folger R, Bies RJ. Managerial responsibilities and procedural justice. Employee responsibilities and rights journal. 1989 Jun 1;2(2):79-90.

[13] Rai GS. Impact of organizational justice on satisfaction, commitment and turnover intention: Can fair treatment by organizations make a difference in their workers' attitudes and behaviors?. Journal of Human Sciences. 2013 Sep 25;10(2):260-284.

[14] Patrick HA. Commitment of Information Technology Employees in Relation to Perceived Organizational Justice. IUP Journal of Organizational Behavior. 2012 Jul 1;11(3)

[15] Colquitt JA, Conlon DE, Wesson MJ, Porter CO, Ng KY. Justice at the millennium: a meta-analytic review of 25 years of organizational justice research. Journal of applied psychology. 2001 Jun;86(3):425

[16] Bass BM, Avolio BJ. Full range leadership development: Manual for the Multifactor Leadership Questionnaire. Mind Garden; 1997.

[17] Eisenberger R, Huntington R, Hutchison S, Sowa D. Perceived organizational support. Journal of Applied psychology. 1986 Aug;71(3):500.

[18] Spector PE. Job satisfaction: Application, assessment, causes, and consequences. Sage publications; 1997 Mar 26.

[19] Baron RM, Kenny DA. The moderator-mediator variable distinction in social psychological research: Conceptual, strategic, and statistical considerations. Journal of personality and social psychology. 1986 Dec;51(6):1173

[20] Hair, J.F.; Black, W.C.; Babin, B.J.; Anderson, R.E.; Tatham, R.L. Multivariate Data Analysis, 6th ed.; Pearson/Prentice-Hall: Upper Saddle River, NJ, USA, 2006.

[21] Sayadi Y. The effect of dimensions of transformational, transactional, and non-leadership on the job satisfaction and organizational commitment of teachers in Iran. Management in Education. 2016 Apr;30(2):57-65.

[22] Tesfaw, A. T. The relationship between transformational leadership and job satisfaction: The case of government secondary school teachers in Ethiopia. Educational Management Administration \& Leadership.2014, 42(6), 903-918.

[23] Cho J, Dansereau F. Are transformational leaders fair? A multi-level study of transformational leadership, justice perceptions, and organizational citizenship behaviors. The Leadership Quarterly. 2010 Jun 1;21(3):409-421. 